\title{
Aquatic habitats of the malaria vector Anopheles funestus in rural south-eastern Tanzania
}

\author{
Ismail H. Nambunga ${ }^{1 *}$, Halfan S. Ngowo ${ }^{1,3}$, Salum A. Mapua 1,5, Emmanuel E. Hape ${ }^{1}$, Betwel J. Msugupakulya ${ }^{1,4}$, \\ Dickson S. Msaky ${ }^{1}$, Nicolaus T. Mhumbira' , Karim R. Mchwembo ${ }^{1}$, Gerald Z. Tamayamali', Slyakus V. Mlembe', \\ Rukiyah M. Njalambaha', Dickson W. Lwetoijera ${ }^{1,4}$, Marceline F. Finda ${ }^{1,2}$, Nicodem J. Govella1,3,4, \\ Damaris Matoke-Muhia ${ }^{1,6}$, Emmanuel W. Kaindoa ${ }^{1,2}$ and Fredros O. Okumu ${ }^{1,2,3,4^{*}}$
}

\begin{abstract}
Background: In rural south-eastern Tanzania, Anopheles funestus is a major malaria vector, and has been implicated in nearly $90 \%$ of all infective bites. Unfortunately, little is known about the natural ecological requirements and survival strategies of this mosquito species.

Methods: Potential mosquito aquatic habitats were systematically searched along $1000 \mathrm{~m}$ transects from the centres of six villages in south-eastern Tanzania. All water bodies were geo-referenced, characterized and examined for presence of Anopheles larvae using standard $350 \mathrm{mLs}$ dippers or $10 \mathrm{~L}$ buckets. Larvae were collected for rearing, and the emergent adults identified to confirm habitats containing An. funestus.

Results: One hundred and eleven habitats were identified and assessed from the first five villages (all $<300 \mathrm{~m}$ altitude). Of these, 36 (32.4\%) had An. funestus co-occurring with other mosquito species. Another 47 (42.3\%) had other Anopheles species and/or culicines, but not An. funestus, and 28 (25.2\%) had no mosquitoes. There were three main habitat types occupied by An. funestus, namely: (a) small spring-fed pools with well-defined perimeters (36.1\%), (b) medium-sized natural ponds retaining water most of the year (16.7\%), and (c) slow-moving waters along river tributaries (47.2\%). The habitats generally had clear waters with emergent surface vegetation, depths $>0.5 \mathrm{~m}$ and distances $<100 \mathrm{~m}$ from human dwellings. They were permanent or semi-permanent, retaining water most of the year. Water temperatures ranged from 25.2 to $28.8^{\circ} \mathrm{C}$, pH from 6.5 to 6.7 , turbidity from 26.6 to 54.8 NTU and total dissolved solids from 60.5 to $80.3 \mathrm{mg} / \mathrm{L}$. In the sixth village (altitude $>400 \mathrm{~m}$ ), very high densities of An. funestus were found along rivers with slow-moving clear waters and emergent vegetation.
\end{abstract}

Conclusion: This study has documented the diversity and key characteristics of aquatic habitats of An. funestus across villages in south-eastern Tanzania, and will form an important basis for further studies to improve malaria control. The observations suggest that An. funestus habitats in the area can indeed be described as fixed, few and findable based on their unique characteristics. Future studies should investigate the potential of targeting these habitats with larviciding or larval source management to complement malaria control efforts in areas dominated by this vector species.

Keywords: Anopheles funestus, Ifakara, Malaria, Tanzania, Larviciding, Larval source management

\footnotetext{
*Correspondence: inambunga@ihi.or.tz; fredros@ihi.or.tz

${ }^{1}$ Environmental Health and Ecological Sciences Department, Ifakara Health Institute, P.O. Box 53, Ifakara, Tanzania

Full list of author information is available at the end of the article
}

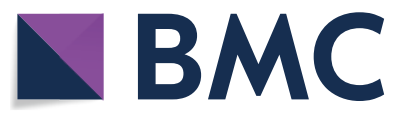

(c) The Author(s) 2020. This article is licensed under a Creative Commons Attribution 4.0 International License, which permits use, sharing, adaptation, distribution and reproduction in any medium or format, as long as you give appropriate credit to the original author(s) and the source, provide a link to the Creative Commons licence, and indicate if changes were made. The images or other third party material in this article are included in the article's Creative Commons licence, unless indicated otherwise in a credit line to the material. If material is not included in the article's Creative Commons licence and your intended use is not permitted by statutory regulation or exceeds the permitted use, you will need to obtain permission directly from the copyright holder. To view a copy of this licence, visit http://creativeco mmons.org/licenses/by/4.0/. The Creative Commons Public Domain Dedication waiver (http://creativecommons.org/publicdomain/ zero/1.0/) applies to the data made available in this article, unless otherwise stated in a credit line to the data. 


\section{Background}

Anopheles funestus has been a major malaria vector in many east and southern African countries for several years [1-4]. In south-eastern Tanzania, they have been implicated in more than $85 \%$ of malaria transmission events across several villages [4-6]. Its dominance in pathogen transmission $[4,7]$ is attributable to factors such as: (a) being predominantly anthropophilic (i.e. strong preference for blood from humans over other vertebrates) and endophilic (i.e. strong preference for biting and resting indoors than outdoors) [8, 9], (b) their resistance to some of the commonly-used pyrethroid insecticides in locations such as south-eastern Tanzania [10-14], and (c) their superior daily survival probabilities as reflected in the higher parity rates compared to other Anopheles species $[4,5,7]$.

The supremacy of An. funestus in malaria transmission has been observed even in areas where they occur at far lower densities compared to other malaria vectors, such as Anopheles arabiensis [4, 5, 15]. In such settings, the infrequent occurrence partly explains why their behaviours are relatively understudied in the field. More generally, An. funestus is also far easier to find as adults than as larvae. As a result, this species rarely features in larval surveys of Anopheles species. Researchers, therefore, sometimes rely on adult collections rather than larval collections to obtain enough samples for insecticide resistance testing [4], which according to the World Health Organization (WHO) protocols require F1 offspring with synchronized age groups [16].

It has previously been suggested that an in-depth ecological understanding, followed by improved targeting of An. funestus could potentially improve their control, and significantly reduce malaria transmission in areas where the vector dominates [4]. Given the strong resistance of some An. funestus populations to insecticides commonly applied on insecticide-treated nets (ITNs) and/or indoor residual spraying (IRS) [10-14], supplementary measures targeting the aquatic stages of the mosquitoes are critical for more effective control of An. funestus. This requires rigorous surveys to identify and characterize preferred larval habitats for An. funestus [17]. Strategies such as targeted larviciding-a component of larval source management could indeed significantly improve control efforts and accelerate progress towards malaria elimination, especially in communities where the aquatic habitats are fixed, few and findable $[18,19]$.

A previous study in western Kenya reported that $A n$. funestus prefers to oviposit in large semi-permanent water bodies containing aquatic vegetation and algae [20]. A separate study in coastal Kenya observed these species breeding in vegetated aquatic habitats that are stable and permanent, and were along river streams
[21]. In Cameroon, it was demonstrated that An. funestus habitats were often found in open savannas instead of deep or degraded forests [22, 23]. These habitats had greater exposure to sunlight and high temperatures, and remained productive for longer, often with peaks after the start of the dry season. Unfortunately, in south-eastern Tanzania where the species now dominates transmission, there have not been detailed studies of its natural aquatic habitats and responses to interventions. This situation is complicated by difficulties in colonizing the species inside laboratories, which would enable such studies.

This current baseline study was, therefore, aimed at identifying and characterizing the main larval habitats of An. funestus to advance knowledge of its aquatic ecology. The findings were expected to provide a basis for further investigations into improved control strategies targeting the species, and also to inform ongoing efforts for rearing this species under laboratory conditions.

\section{Methods \\ Study areas}

This study was conducted in six villages of Kilombero and Ulanga districts in south-eastern Tanzania (Fig. 1). Five of these villages were located at altitudes less than $300 \mathrm{~m}$ above sea level, while the sixth was at an altitude greater than $400 \mathrm{~m}$. In Kilombero district, the study villages were Ikwambi $\left(-7.97927^{\circ} \mathrm{S}, 36.81630^{\circ} \mathrm{E}\right)$, Kisawasawa $\left(-7.89657^{\circ} \mathrm{S}, 36.88058^{\circ} \mathrm{E}\right)$ and Mpofu $\left(-8.17220^{\circ}\right.$ $\left.\mathrm{S}, 36.21651^{\circ} \mathrm{E}\right)$, while in Ulanga district, the villages were Kilisa $\left(-8.37544^{\circ} \mathrm{S}, 36.57355^{\circ} \mathrm{E}\right)$, Ruaha $\left(-8.9063^{\circ} \mathrm{S}\right.$, $\left.36.7194^{\circ} \mathrm{E}\right)$ and Tulizamoyo $\left(-8.35447^{\circ} \mathrm{S}, 36.70546^{\circ} \mathrm{E}\right)$. The study villages were selected based on the high abundance of adult An. funestus mosquitoes based on previous surveillance work done by Ifakara Health Institute (unpublished data). The annual rainfall and temperature ranges in these villages were $1200-1800 \mathrm{~mm}$ and $20-32.6^{\circ} \mathrm{C}$ respectively. The main economic activities are crop farming (mostly rice and maize farming) and livestock keeping.

\section{Larvae collection and rearing}

This study was done between January and September 2018, and repeated between October and December 2019. The study villages were surveyed for the presence of aquatic habitats along transects of $1000 \mathrm{~m}$, each radiating from an approximated village centroid. All identified water bodies were marked, geo-referenced, physically characterized and examined for the presence of Anopheles larvae. Standard $350 \mathrm{~mL}$ dippers or $10 \mathrm{~L}$ plastic buckets were used to sample water from the pools (Fig. 2). When the water bodies consisted of rivers and streams, larval sampling was done along the river length over distances not exceeding $1000 \mathrm{~m}$, so as to match the $1000 \mathrm{~m}$ 


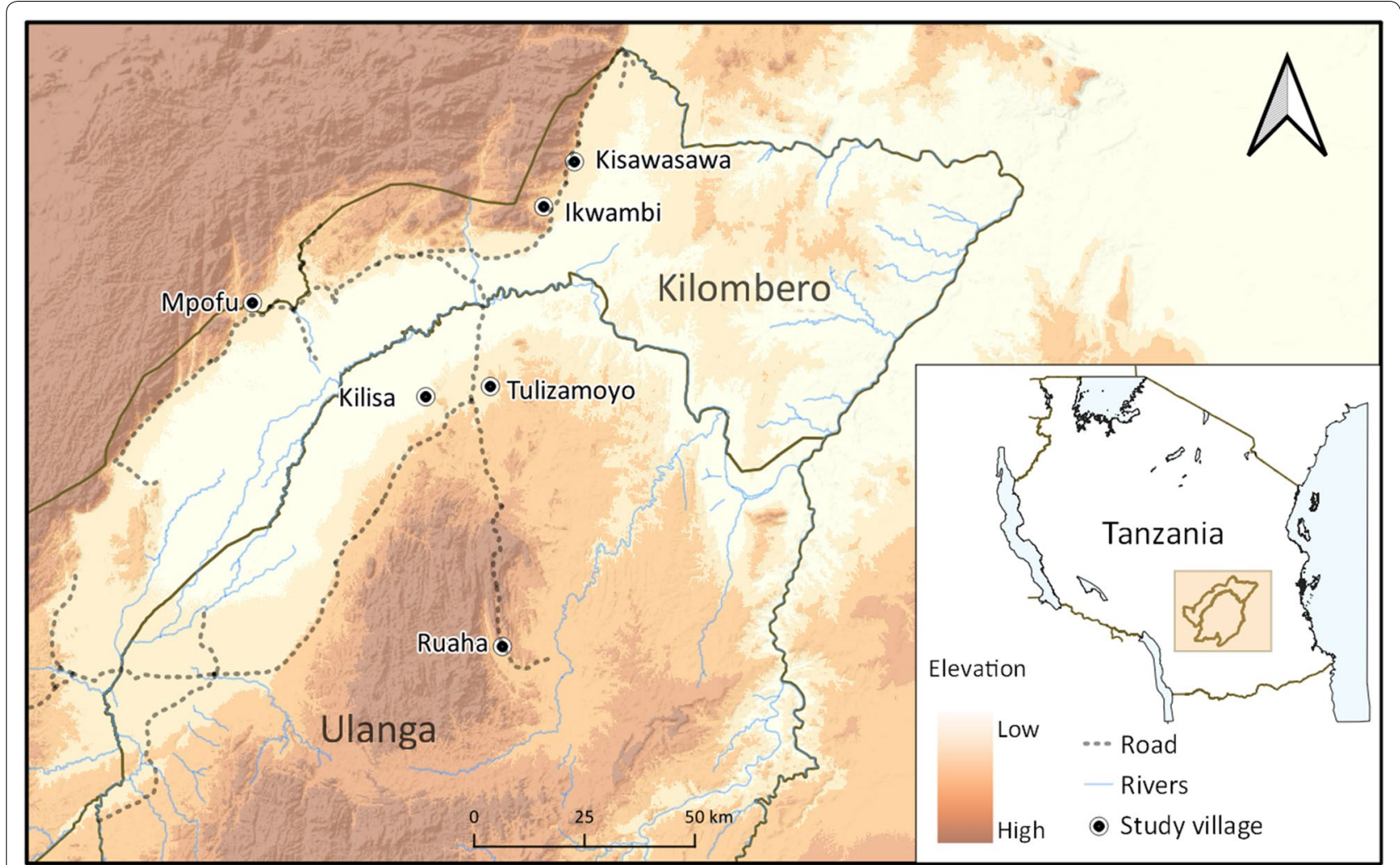

Fig. 1 Map of Kilombero and Ulanga districts showing the six study villages

transects in the main survey. Parts of the rivers with or without Anopheles larvae were similarly characterized and geo-referenced. The buckets were used in sites where it was impractical to use the dippers (e.g. habitats with depths greater than $50 \mathrm{~cm}$ ), and also to collect the larvae for further rearing and identification. The larvae collected from different aquatic sites were transported to the insectary at Ifakara Health Institute for rearing to adults.

Once in the insectary, the larvae were kept in rearing pans (32 $\mathrm{cm}$ diameter and $5 \mathrm{~L}$ holding capacity) labelled with information on the dates and place of larvae collection. The temperature in the insectary was kept at $26{ }^{\circ} \mathrm{C} \pm 2{ }^{\circ} \mathrm{C}$ and relative humidity at $82 \% \pm 10 \%$. The larvae were fed with Tetramin ${ }^{\circledR}$ fish food until they developed into pupae and emerged into adult mosquitoes. Emerging adult mosquitoes were collected using mouth aspirator, killed by freezing and all Anopheles were identified using morphology-based identification keys developed by Gilles and Coetzee [9, 24]. All identified An. funestus mosquitoes were then packed individually in $1.5 \mathrm{~mL}$ Eppendorf tubes with silica gel and submitted to molecular laboratory for sibling species identification by polymerase chain reaction (PCR) assays as described by Koekemoer et al. [25]. Habitats positive for An. funestus were then identified among all the surveyed habitats.

\section{Characteristics of aquatic habitats}

Characteristics of all the aquatic habitats as well as the surrounding environments were recorded. For the habitats, information collected included water movement (stagnant or slow), water colour (clear, coloured, or polluted), a tree canopy (shade) over habitat (none, partial, heavy), habitat size in circumference (less than $10 \mathrm{~m}$, between 10 and $100 \mathrm{~m}$, more than $100 \mathrm{~m}$ ), vegetation type (none, submerged, floating, emergent), vegetation quantity (none, scarce, moderate, abundant), algae quantity (none, scarce, moderate), water depth (less than $10 \mathrm{~cm}$, between 10 and $50 \mathrm{~cm}$, more than $50 \mathrm{~cm}$ ), distance from the nearest homes (less than $100 \mathrm{~m}$, between 100 and $500 \mathrm{~m}$, more than $500 \mathrm{~m}$ ) and water type (semipermanent, permanent). The habitats were considered temporary, semi-permanent or permanent if retained water for less than 3 months, 3-9 months and throughout the year respectively.

Additionally, the physicochemical characteristics of water in the larval habitats were assessed in four of the six villages, namely Tulizamoyo, Ikwambi, Kisawasawa and Kilisa. Parameters assessed included: water temperature $\left({ }^{\circ} \mathrm{C}\right), \mathrm{pH}$ (scale of $\left.0-14\right)$, conductivity $($ Siemens $/ \mathrm{m})$, total dissolved solids $(\mathrm{mg} / \mathrm{L})$ and turbidity (nephelometric turbidity units, using $2100 \mathrm{Q}$ 

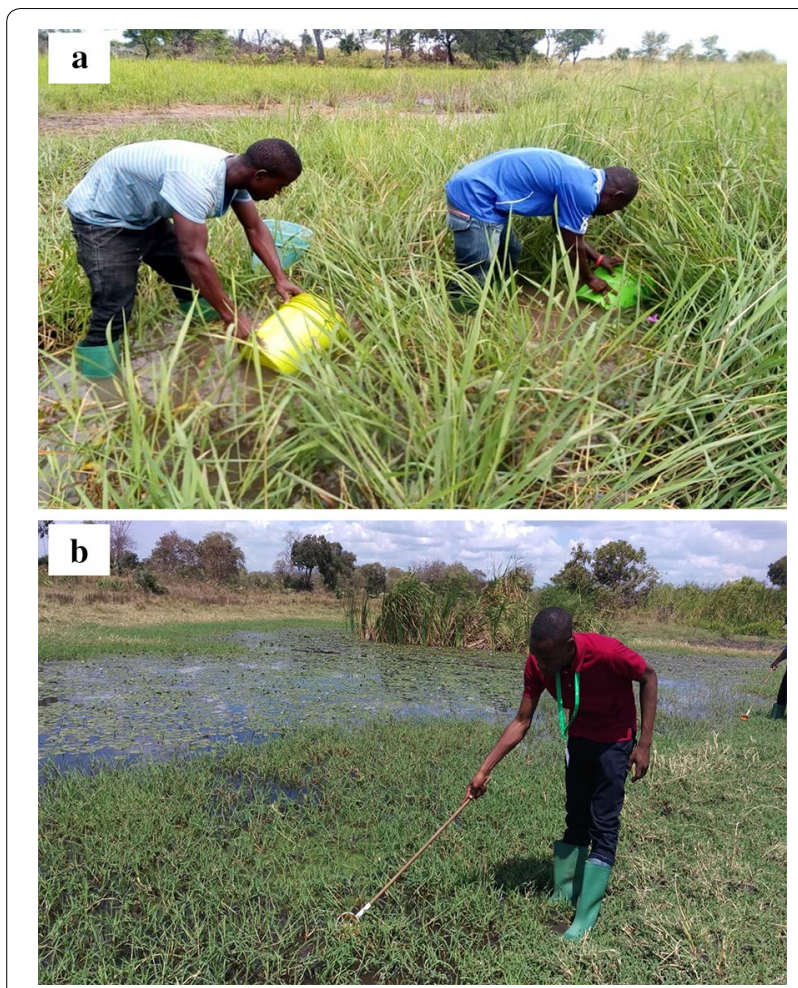

Fig. 2 Collection of An. funestus larvae using $10 \mathrm{~L}$ bucket (a) and standard dipper (b)

portable turbidity meter). Assessments of these parameters were conducted in the field sites immediately after the collection of larvae from the habitats. Lastly, nitrate levels (milligrams per litre) were also analysed by spectrophotometric method. To do this, one litre of water samples from each habitat in the study sites was collected, stored in a cooler box and sent to the laboratory at Ifakara Health Institute for analysis within $24 \mathrm{~h}$ post collection.

\section{Data analysis}

Analysis was done using open source software, R programming language [26]. A total of 16 environmental variables were used to identify the main predictors for the presence of An. funestus larvae in the study villages. At first, all main predictors were initially assessed individually using univariate logistic regression and assess its impact on the presence of An. funestus larvae. Secondly, all the variables were included in the final model and assess their effect on the presence of An. funestus larvae. Odds ratios and their 95\% confidence intervals are reported, and the statistical differences were considered significant when P-values $<0.05$.

\section{Results}

Occurrence of An. funestus and other mosquito species in different habitats

A total of 111 potential habitats were surveyed of which $83(74.8 \%)$ were identified to have larvae while 28 (25.2\%) did not have. Of the 83 larval habitats that were positive for mosquito larvae, 36 (43.4\%) had An. funestus. More than two-thirds of the An. funestus habitats (69.4\%; $\mathrm{n}=25)$ were shared with Culex mosquitoes, while one third $(30.6 \% ; \mathrm{n}=11)$ were shared with other Anopheles species. The An. funestus habitats included: springfed pools (36.1\%; $n=13)$, medium-sized natural ponds $(16.7 \% ; \mathrm{n}=6)$ and river tributaries with slow-moving waters $(44.2 \% ; \mathrm{n}=17)$.

Adult mosquitoes that emerged from the different sampled habitats consisted of: An. funestus sensu lato (s.l.) $(64 \% ; \mathrm{n}=696)$, Culex spp. $(24.5 \% ; \mathrm{n}=267)$, Anopheles coustani $(6.2 \% ; \mathrm{n}=67)$, Anopheles gambiae s.l. (4.3\%; $\mathrm{n}=47)$ and other species $(1 \%$; $=11)$. PCR identification of the 501 An. funestus group revealed that $53.3 \%$ $(\mathrm{n}=267)$ were $A n$. funestus sensu stricto (s.s.), 28.7\% $(\mathrm{n}=144)$ were Anopheles rivulorum, 11.8\% $(\mathrm{n}=59)$ were Anopheles leesoni and $6.2 \%(\mathrm{n}=31)$ were unidentified due to non-amplification in the PCR assays. The An. funestus s.s. commonly shared habitats with the other sibling species including An. leesoni and An. rivulorum.

\section{Habitat characteristics}

Table 1 summarizes different environmental variables in aquatic habitats associated with the presence of $A n$. funestus and other mosquito species. These variables were assessed individually and later combined in the final model to see how they influence the presence of $A n$. funestus larvae. Results from univariate logistic regression showed that, the permanent habitats with emergent vegetation were strongly associated with the presence of An. funestus larvae $(\mathrm{P}<0.01)$. The final model, multivariate outputs show that stagnant or slow-moving water did not significantly affect the presence of An. funestus larvae from the observed aquatic habitats (Table 2). However, heavily shaded aquatic habitats (with high densities of tree canopy), especially along the rivers were more likely to harbour An. funestus larvae compared to others (Table 2). Furthermore, the aquatic habitats with a depth greater than $50 \mathrm{~cm}$ and vegetation were significantly associated with the presence of An. funestus larvae (Table 2).

At higher altitudes, such as in Ruaha village, which was higher than $400 \mathrm{~m}$ above sea level, all the An. funestus larvae collected were from the rivers. The river sections acting as the breeding sites for An. funestus had slow-moving and clear waters near their banks. They 
Table 1 Characteristics of aquatic habitats of An. funestus and other mosquito species

\begin{tabular}{|c|c|c|c|c|c|}
\hline Larval habitat & $\begin{array}{l}\text { All water bodies } \\
\text { n (\%) }\end{array}$ & $\begin{array}{l}\text { Water bodies } \\
\text { without larvae } \\
\mathrm{n}(\%)\end{array}$ & $\begin{array}{l}\text { Habitats with An. } \\
\text { funestus } \\
\mathrm{n}(\%)\end{array}$ & $\begin{array}{l}\text { Habitats with other } \\
\text { Anopheles } \\
\mathrm{n}(\%)\end{array}$ & $\begin{array}{l}\text { Habitats } \\
\text { with culicines } \\
\text { n (\%) }\end{array}$ \\
\hline \multicolumn{6}{|l|}{ Water movement } \\
\hline Stagnant & $91(82)$ & $25(89.3)$ & $27(75)$ & $18(75)$ & $21(91.3)$ \\
\hline Slow & $20(18)$ & $3(10.7)$ & $9(25)$ & $6(25)$ & $2(8.7)$ \\
\hline \multicolumn{6}{|c|}{ Habitat shade (density of tree canopy) } \\
\hline None & $60(54.1)$ & $11(39.3)$ & $17(47.2)$ & $18(75)$ & $14(60.9)$ \\
\hline Partial & $35(31.5)$ & $14(50)$ & $11(30.6)$ & $4(16.7)$ & $6(26.1)$ \\
\hline Heavy & $16(14.4)$ & $3(10.7)$ & $8(22.2)$ & $2(8.3)$ & $3(13)$ \\
\hline \multicolumn{6}{|l|}{ Water depth } \\
\hline Less than $50 \mathrm{~cm}$ & $51(45.9)$ & $12(42.9)$ & $12(33.3)$ & $17(70.8)$ & $10(43.4)$ \\
\hline Greater than $50 \mathrm{~cm}$ & $60(54.1)$ & $16(57.1)$ & $24(66.7)$ & $7(29.2)$ & $13(56.6)$ \\
\hline \multicolumn{6}{|c|}{ Distance to human dwellings } \\
\hline Less than $100 \mathrm{~m}$ & $77(69.4)$ & $26(92.9)$ & $28(77.8)$ & $9(37.5)$ & $14(60.9)$ \\
\hline Greater than $100 \mathrm{~m}$ & $34(3.6)$ & $2(7.1)$ & $8(22.2)$ & $15(62.5)$ & $9(39.1)$ \\
\hline \multicolumn{6}{|l|}{ Water type } \\
\hline Permanent & 44 (39.6) & $7(25)$ & $21(58.3)$ & $7(29.2)$ & $9(39.1)$ \\
\hline Semi-permanent & $67(60.4)$ & $21(75)$ & $15(41.7)$ & $17(70.8)$ & $14(60.9)$ \\
\hline \multicolumn{6}{|l|}{ Vegetation type } \\
\hline Emergent & $51(46)$ & $6(21.4)$ & $26(72.2)$ & $7(29.2)$ & $12(52.2)$ \\
\hline Submerged & $11(9.9)$ & $7(25)$ & $1(2.8)$ & $1(4.2)$ & $2(8.7)$ \\
\hline None & $25(22.5)$ & $12(42.9)$ & $3(8.3)$ & $6(25)$ & $4(17.4)$ \\
\hline Floating & $24(21.6)$ & $3(10.7)$ & $6(16.7)$ & $10(41.6)$ & $5(21.7)$ \\
\hline \multicolumn{6}{|l|}{ Water colour } \\
\hline Clear & $59(53.2)$ & $7(25)$ & $29(80.5)$ & $15(62.5)$ & $8(34.8)$ \\
\hline Coloured & $42(37.8)$ & $18(64.3)$ & $6(16.7)$ & 8 (33.3) & $10(43.5)$ \\
\hline Polluted & $10(9)$ & $3(10.7)$ & $1(2.8)$ & $1(4.2)$ & $5(21.7)$ \\
\hline \multicolumn{6}{|l|}{ Vegetation quantity } \\
\hline None & $24(21.6)$ & $11(39.3)$ & $3(8.3)$ & $6(25)$ & $4(17.4)$ \\
\hline Scarce & $57(51.4)$ & $15(53.5)$ & $15(41.7)$ & $12(50)$ & $15(65.2)$ \\
\hline Moderate & $22(19.8)$ & $1(3.6)$ & $13(36.1)$ & $5(20.8)$ & $3(13.1)$ \\
\hline Abundant & $8(7.2)$ & $1(3.6)$ & $5(13.9)$ & $1(4.2)$ & $1(4.2)$ \\
\hline \multicolumn{6}{|l|}{ Algae quantity } \\
\hline None & $70(63.1)$ & $14(50)$ & $21(58.3)$ & $18(75)$ & $17(73.9)$ \\
\hline Scarce & $32(28.8)$ & $11(39.3)$ & $13(36.1)$ & $4(16.7)$ & $4(17.4)$ \\
\hline Moderate & $9(8.1)$ & $3(10.7)$ & $2(5.6)$ & $2(8.3)$ & $2(8.7)$ \\
\hline \multicolumn{6}{|l|}{ Habitat size } \\
\hline Less than $10 \mathrm{~m}$ & $61(55)$ & $22(78.6)$ & $13(36.1)$ & $12(50)$ & $14(60.9)$ \\
\hline Between 10 and $100 \mathrm{~m}$ & $46(41.4)$ & $6(21.4)$ & $21(58.3)$ & $11(45.8)$ & $8(34.8)$ \\
\hline Greater than $100 \mathrm{~m}$ & $4(3.6)$ & $0(0)$ & $2(5.6)$ & $1(4.2)$ & $1(4.3)$ \\
\hline
\end{tabular}

were characterized by abundant emergent vegetation and water depths of greater than $50 \mathrm{~cm}$ (Fig. 3), and were within $100 \mathrm{~m}$ from human dwellings. The physical characteristics at these altitudes were the same as in the other habitats of An. funestus found below $300 \mathrm{~m}$ altitude, i.e. the natural perennial ponds, or small springfed water pools with well-defined areas (Figs. 4 and 5).

\section{Physicochemical characteristics of water in the aquatic} habitats

Table 3 shows the median values of physicochemical parameters in larval habitats of different mosquito species. The $\mathrm{pH}$ in all An. funestus larval habitats were weakly acidic, ranging from 6.5 to 6.7 . The concentration of total dissolved solids (tds) was highest in the water 
Table 2 Results of univariate and multivariate regression analysis of different habitat characteristics and their association with presence of $A n$. funestus larvae

\begin{tabular}{|c|c|c|c|c|}
\hline \multirow[t]{2}{*}{ Larval habitat } & \multicolumn{2}{|l|}{ Univariate analysis } & \multicolumn{2}{|l|}{ Multivariate analysis } \\
\hline & Odds (95\% LC, UC) & P-values & Odds (95\% LC, UC) & P-values \\
\hline \multicolumn{5}{|l|}{ Water movement } \\
\hline Stagnant & 1 & & 1 & \\
\hline Slow & $1.94[0.72,5.21]$ & 0.189 & $3.71[0.81,17.00]$ & 0.091 \\
\hline \multicolumn{5}{|c|}{ Habitat shading (density of tree canopy) } \\
\hline None & 1 & & 1 & \\
\hline Partial & $1.16[0.47,2.87]$ & 0.750 & $0.84[0.22,3.24]$ & 0.795 \\
\hline Heavy & $2.53[0.82,7.83]$ & 0.107 & $7.35[1.04,51.78]$ & $<0.05$ \\
\hline \multicolumn{5}{|l|}{ Water depth } \\
\hline Less than $50 \mathrm{~cm}$ & 1 & & 1 & \\
\hline Greater than $50 \mathrm{~cm}$ & $2.17[0.95,4.96]$ & 0.067 & $5.72[1.40,23.42]$ & $<0.05$ \\
\hline \multicolumn{5}{|c|}{ Distance to human dwellings } \\
\hline Less than $100 \mathrm{~m}$ & 1 & & 1 & \\
\hline Greater than 100 m & $0.54[0.21,1.35]$ & 0.186 & $0.43[0.12,1.49]$ & 0.184 \\
\hline \multicolumn{5}{|l|}{ Water type } \\
\hline Semi-permanent & 1 & & 1 & \\
\hline Permanent & $3.16[1.39,7.23]$ & $<0.01$ & $3.07[0.86,10.99]$ & 0.085 \\
\hline \multicolumn{5}{|l|}{ Vegetation type } \\
\hline None & 1 & & 1 & \\
\hline Submerged & $0.73[0.07,7.95]$ & 0.799 & $0.55[0.21,1.42]$ & 0.216 \\
\hline Emergent & $7.63[2.03,28.70]$ & $<0.01$ & $1.96[0.66,5.78]$ & 0.966 \\
\hline Floating & $2.44[0.53,11.17]$ & 0.249 & $0.92[0.03,31.86]$ & 0.962 \\
\hline \multicolumn{5}{|l|}{ Water colour } \\
\hline Clear & 1 & & 1 & \\
\hline Coloured & $0.17[0.06,0.47]$ & $<0.001$ & $0.10[0.02,0.46]$ & $<0.01$ \\
\hline Polluted & $0.11[0.01,0.97]$ & $<0.05$ & $0.15[0.01,1.72]$ & 0.127 \\
\hline \multicolumn{5}{|l|}{ Vegetation quantity } \\
\hline None & 1 & & 1 & \\
\hline Scarce & $2.50[0.65,9.60]$ & 0.182 & $12.62[1.76,90.55]$ & $<0.05$ \\
\hline Moderate & $10.11[2.31,44.35]$ & $<0.01$ & $20.03[2.41,166.2]$ & $<0.01$ \\
\hline Abundant & $11.67[1.79,76.01]$ & $<0.05$ & $22.96[1.33,395.7]$ & $<0.05$ \\
\hline \multicolumn{5}{|l|}{ Algae quantity } \\
\hline None & 1 & & 1 & \\
\hline Scarce & $1.60[0.67,3.82]$ & 0.293 & $5.40[1.35,21.64]$ & $<0.05$ \\
\hline Moderate & $0.67[0.13,3.48]$ & 0.631 & $0.50[0.03,7.97]$ & 0.623 \\
\hline \multicolumn{5}{|l|}{ Habitat size } \\
\hline Less than $10 \mathrm{~m}$ & 1 & & 1 & \\
\hline Between 10 and $100 \mathrm{~m}$ & $3.10[1.33,7.21]$ & $<0.01$ & $1.37[0.37,5.04]$ & 0.638 \\
\hline Greater than $100 \mathrm{~m}$ & $3.69[0.47,28.78]$ & 0.212 & $1.17[0.08,17.07]$ & 0.910 \\
\hline
\end{tabular}

pools without any larvae $(88.7-148.0 \mathrm{mg} / \mathrm{L})$ and lowest in An. funestus habitats $(60.5-80.3 \mathrm{mg} / \mathrm{L})$. Turbidity was low in all habitats surveyed (11.5-64.0 NTU), while conductivity was higher in water pools without larvae (286.0 [99.2-310.0] $\mu \mathrm{S} / \mathrm{cm})$ compared to habitats containing An. funestus (151.0 [134.0-165.0] $\mu \mathrm{S} / \mathrm{cm})$ and others. The association between these physicochemical characteristics and the occurrence of An. funestus was however not statistically significant at $\mathrm{P}<0.05$ (Table 4).

\section{Discussion}

Although An. funestus are among the most important vectors of malaria in Africa, little is known regarding their larval ecology and development. This crucial 


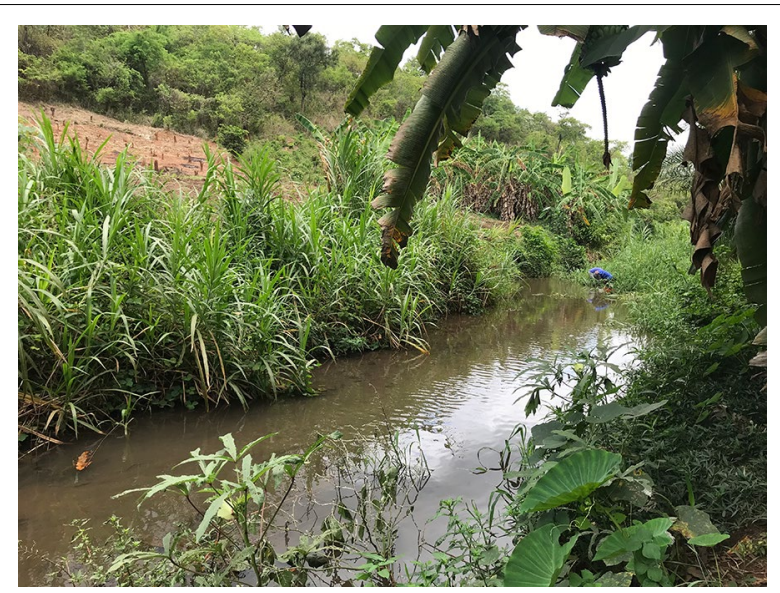

Fig. 3 Picture of a riverside aquatic habitat for Anopheles funestus mosquitoes, as identified in the study areas in rural south-eastern Tanzania. At altitudes above $400 \mathrm{~m}$, these were the only An. funestus habitats identified gap needs an urgent solution, but is perpetuated by the inability of most mosquito biologists to create laboratory colonies of this vector species. Understanding the basic environmental parameters that influence mosquitoes breeding and oviposition can improve the planning, development and deployment of new interventions to control malaria transmission [27]. This study identified and characterized larval habitats of An. funestus in southeastern Tanzanian villages of Ulanga and Kilombero districts, where this mosquito species has been implicated in most malaria-infective bites $[4,6]$.

The study examined more than 100 potential habitats across six villages and identified three main habitat types. First were small water wells with well-defined edges and were spring-fed, some of which were also used by locals as domestic water sources (Fig. 4b). These habitats were often occupied by multiple species of the $A n$. funestus group, and in some cases, they were shaded by large trees. The second type of habitat was mediumsized ponds, for which the central part retained water
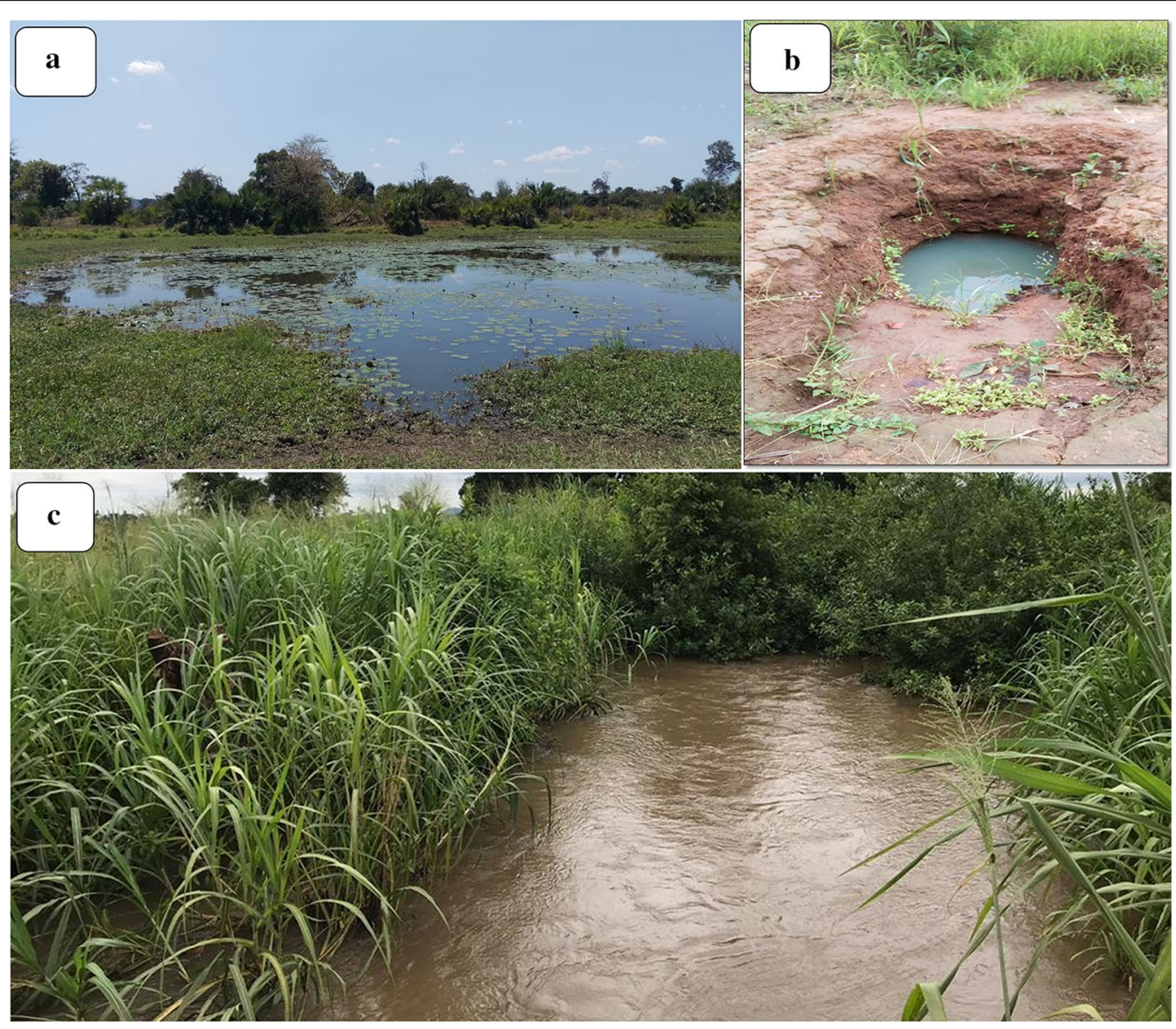

Fig. 4 Typical larval habitats of Anopheles funestus mosquitoes in lower altitude areas (a medium-sized ponds that retain water at the centre most of the year and have emergent surface vegetation and $\mathbf{b}$ small spring-fed wells with well-defined perimeters) and habitats at higher altitudes (c slow-moving waters at the riverside with emergent vegetation) 
Table 3 Median values of key physicochemical parameters in aquatic habitats dominated by different mosquito species

\begin{tabular}{lllllll}
\hline Dominant mosquito species & $\mathbf{p H}$ & Turbidity (NTU) & Temp $\left({ }^{\circ} \mathbf{C}\right)$ & Conductivity $(\boldsymbol{\mu S} / \mathbf{c m})$ & TDS (mg/L) & Nitrate (mg/L) \\
\hline Anopheles funestus & $6.6(6.5-6.7)$ & $32.9(26.6-54.8)$ & $27.1(25.2-28.8)$ & $151.0(134-165)$ & $69.7(60.5-80.3)$ & $4.1(2.9-6.6)$ \\
Culicine mosquitoes & $6.2(5.9-6.5)$ & $36.0(19.8-43.2)$ & $26.5(25.1-27.3)$ & $161.0(106-189)$ & $78.8(53.1-112.0)$ & $2.7(1.6-3.7)$ \\
Other Anopheles & $6.8(6.4-7.1)$ & $24.9(19.4-64.0)$ & $28.9(23.2-32.6)$ & $211.0(123-251)$ & $102.0(50.3-108.0)$ & $10.3(2.4-45.5)$ \\
Without larvae & $6.41(5.8-6.7)$ & $15.6(11.5-20.2)$ & $25.6(24.5-27.0)$ & $286.0(99.2-310.0)$ & $142.0(88.7-148.0)$ & $2.45(1.4-2.9)$ \\
\hline
\end{tabular}

Table 4 Univariate and multivariate analysis of associations between physicochemical parameters and the presence of An. funestus larvae

\begin{tabular}{|c|c|c|c|c|}
\hline \multirow[t]{2}{*}{ Characteristics } & \multicolumn{2}{|l|}{ Univariate analysis } & \multicolumn{2}{|l|}{ Multivariate analysis } \\
\hline & Odds ( $95 \%$ LC, UC) & P-values & Odds (95\% LC, UC) & $P$ value \\
\hline $\mathrm{pH}$ & $1.40[0.57,3.44]$ & 0.458 & $3.77[0.96,14.84]$ & 0.057 \\
\hline Temperature & $0.99[0.86,1.14]$ & 0.896 & $0.92[0.76,1.12]$ & 0.403 \\
\hline Nitrate & $0.98[0.94,1.02]$ & 0.368 & $0.94[0.83,1.01]$ & 0.073 \\
\hline TDS & $0.99[0.98,1.00]$ & 0.197 & $0.98[0.94,1.02]$ & 0.248 \\
\hline Turbidity & $1.01[0.99,1.01]$ & 0.285 & $1.01[0.99,1.02]$ & 0.231 \\
\hline Conductivity & $1.00[0.99,1.00]$ & 0.272 & $1.01[0.99,1.02]$ & 0.507 \\
\hline
\end{tabular}

for all or most of the year. These habitats often had surface vegetation (Fig. 4a) and were occupied by multiple other Anopheles species, such as An. arabiensis. Third was the riverside habitats consisting of the slow-moving waters on the rivers or river tributaries, also with vegetation (Fig. 4c). These habitats were mostly found at altitudes above $400 \mathrm{~m}$ above sea level, unlike the other two habitats which were more common at lower altitudes below $300 \mathrm{~m}$ (Fig. 5). In summary, An. funestus in this area appears to prefer permanent and semi-permanent aquatic habitats with stagnant or slow-moving waters, emergent vegetation e.g. algae on swamp surfaces, clear waters at depths exceeding $50 \mathrm{~cm}$ and nearness to human dwellings.

This study provides a basis for designing future surveys and control operations targeting malaria, especially in places such as south-eastern Tanzania where $A n$. funestus and $A n$. arabiensis play a major role in malaria transmission [5, 6, 28-30]. This study has suggested that permanent or semi-permanent habitats characterized by emergent vegetation play a major role in the ecology of An. funestus. The findings are concurrent with past evidence from earlier investigations in Kenya [20, 21, 31]. Although this current study did not assess the seasonality of $A n$. funestus larvae densities in the different habitats, the observed preference of permanent and semi-permanent water bodies explains the known seasonality of its adult densities in the same study villages as observed in recent entomological surveys [4, 30]. The adult densities of $A n$. funestus tend to peak after the rains just before the dry seasons begin, and are sustained by the large permanent water bodies [20]. Although no detailed studies have been done in this area targeting $A n$. funestus aquatic habitats, early accounts by Gillies and DeMeillon [9], as well as limited surveys done nearly 50 years ago in the Ifakara area (which neighbours the current study site) already suggested an association between the late peaks in $A n$. funestus densities and the large perennial habitats [32].

Although there was no clear statistical association, the An. funestus habitats had depths greater than $50 \mathrm{~cm}$ and were located within $100 \mathrm{~m}$ from the human dwellings. This is likely due to the anthropophagic nature of these mosquitoes [33], and further explains the importance of this species in malaria transmission in these areas. Other Anopheles species, such as An. gambiae, which breed in open sunlit stagnant water pools $[9,20,34]$ are also highly anthropophagic and generally occur near human habitations [35]. The ability of An. funestus to breed in the river waters is not unique to Tanzania, but has also been demonstrated in other places such as coastal Kenya [9, 21], and may be due to the higher levels of aeration and dissolved oxygen in such waters. Additional investigations are therefore required to further examine these details. A similar ecological niche has been described for Anopheles pseudopunctipennis in South America, which was successfully controlled by clearing the river waters of the algal blooms [36]. While it is unclear whether clearing the identified habitats of emergent vegetation would be suitable for control of An. funestus in Tanzania, it 


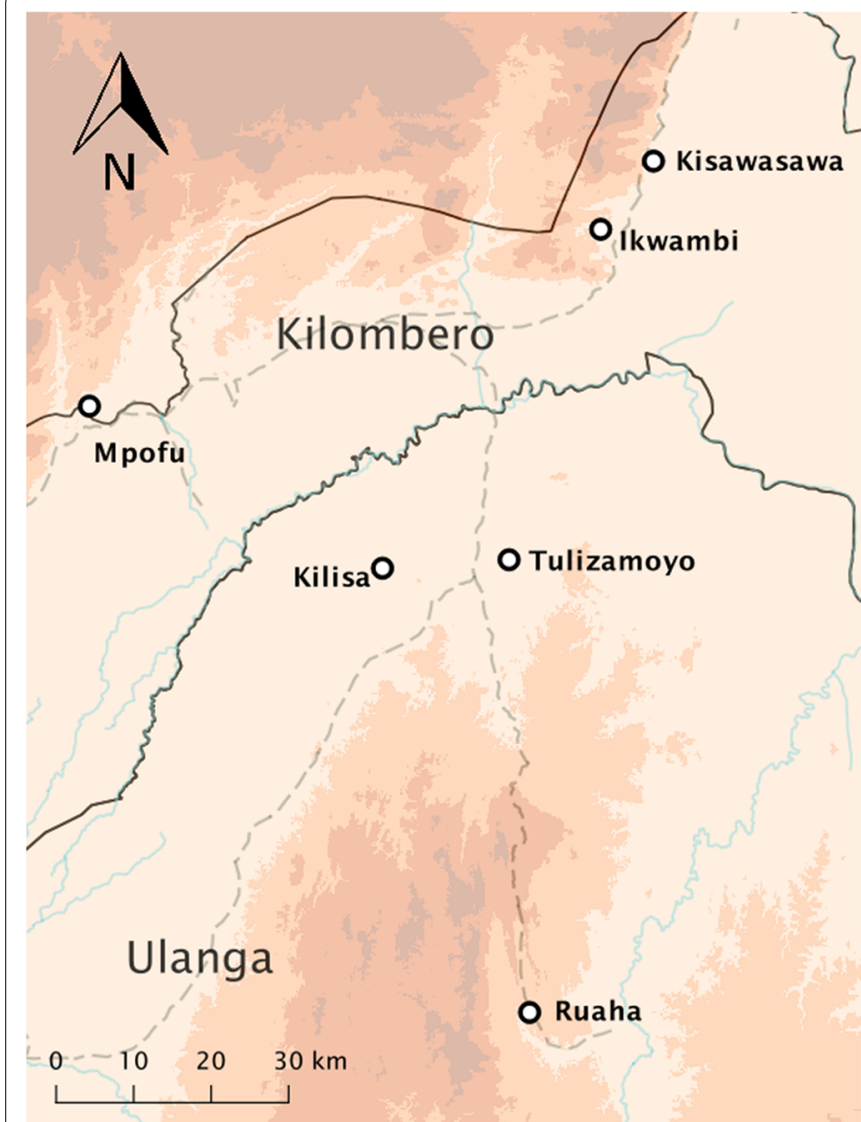

Elevation

Low

High
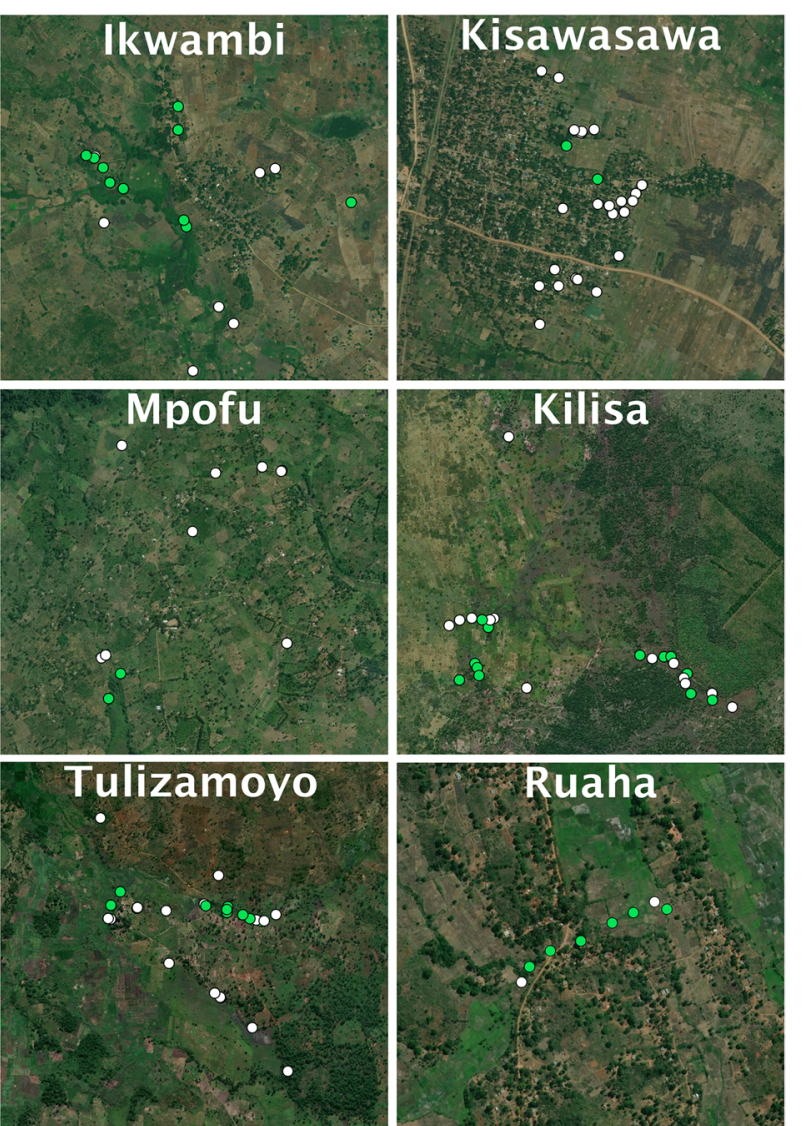

Positive habitats An. funestus

$\bigcirc$ Negative habitats An. funestus

Fig. 5 Spatial distribution of Anopheles funestus larval habitats in the selected study villages in south-eastern Tanzania

will be important to investigate it as a potential environmentally-friendly approach, in which community members could be engaged to achieve effective disease prevention. Besides, it will be important to ascertain the importance of these habitat types across multiple sites and settings. For instance, in one area in the north of Tanzania, Dida et al. [37] found no mosquito larvae near the main rivers, suggesting the dominant malaria vectors may be breeding elsewhere in such settings.

Understanding the physicochemical characteristics of mosquito larval habitats is also important in understanding their overall ecological needs, and assessing options for manipulation. It is probably that the physicochemical parameter levels observed in this study might have been influenced by agricultural practices and pesticide use, which is widespread in the valley [38]. Emerging adult mosquitoes from these habitats might become more resistant towards the insecticides having the same chemical formula used in mosquito vector control $[35,39,40]$.
Habitats most productive of An. funestus were those in higher altitude villages, which were probably less affected by agricultural insecticidal deposits [41, 42], than habitats at the floor of the valley. Nonetheless, the mosquito species from the same study villages are known to be already strongly resistant to insecticides used for public health, including pyrethroids and carbamates [43], a situation potentially related to the widespread use of pesticides in both agriculture and public health. Similar to other studies on Anopheles mosquitoes, the An. funestus habitats in this study area had weak acidity $\mathrm{pH}[40,44]$. The main habitats had $\mathrm{pH}$ ranging from 6.5 to 6.7 , turbidity from 26.6 to $54.8 \mathrm{NTU}$ and total dissolved solids from 60.5 to $80.3 \mathrm{mg} / \mathrm{L}$, all of which are similar to most observations of habitats of Anopheles mosquitoes in previous studies [45, 46]. Anopheles funestus mosquitoes were collected from the habitats with different concentrations of nitrate, but it remains unclear whether this might influence larval development as earlier described [40]. 
One limitation of this study was that some characteristics such as water temperature, though included in this analysis are subject to change during the day. Future studies should consider laboratory investigations and also the use of field data collected multiple times a day to determine the suitable temperature ranges and other physicochemical characteristics for optimal survival of this mosquito species.

\section{Conclusion}

Overall, this study has provided a basic description of An. funestus habitats in rural south-eastern Tanzanian districts of Ulanga and Kilombero. There were three main habitat types occupied by An. funestus, namely: (a) small spring-fed pools with well-defined perimeters, (b) medium-sized natural ponds retaining water most of the year, and (c) slow-moving waters along river tributaries particularly important at higher altitudes at the edge of the valley. The habitats generally had clear waters with emergent surface vegetation, depths greater than $0.5 \mathrm{~m}$ and distances less than $100 \mathrm{~m}$ from human dwellings. They were permanent or semi-permanent, retaining water most of the year. Effective control measures for this species should consider understanding their behaviour and ecology including characteristics of their aquatic habitats so that they can be targeted during their immature stages. Given the rarity of the An. funestus habitats and the observed characteristics, these habitats fit the description of being fixed, few and findable. Future studies should, therefore, investigate the potential of using larviciding or larval source management to improve malaria control in settings where An. funestus dominate.

\section{Abbreviations \\ WHO: World Health Organization; PCR: Polymerase chain reaction; NTU: Nephelometric turbidity unit; LLINs: Long-lasting insecticide-treated nets; IRS: Indoor Residual Spraying; LC: Lower class limit; UC: Upper-class limit.}

\section{Acknowledgements}

Many thanks to the members of the villages where the study was conducted for providing the greater cooperation and support during the study.

\begin{abstract}
Authors' contributions
IHN and FOO conceived the study, developed the research idea and study protocol and produced initial and final drafts of the manuscript. IHN, HSN and FOO analyzed the data. EEH and SVM assisted in molecular identification of species and physicochemical analysis respectively. IHN, DSM and BJM produced the study site maps. IHN, NTM, KRM and GZT identified and characterized the larval habitats. IHN, HSN, EWK, MFF, BJM, RMN, SAM, DMM, $\mathrm{EEH}, \mathrm{DWL}, \mathrm{NJG}$ and FOO contributed to drafting the manuscript. All authors have contributed to the final manuscript. All authors read and approved the final manuscript.
\end{abstract}

\section{Funding}

The activities in this work were supported by Howard Hughes Medical Institute (HHMI) — Gates International Research Scholar Award to FO at Ifakara Health Institute (OPP1175877) and Bill \& Melinda Gates Foundation Grant, also to Ifakara Health Institute (OPP1177156).

\section{Availability of data and materials}

All data generated from this study will be available from the corresponding author as per request.

\section{Ethics approval and consent to participate}

Ethical approval for this study was obtained from Ifakara Health Institute Institutional Review Board (IHI/IRB/No:19-2017), and National Institute of Medical Research (NIMR) through the Medical Research Coordinating Committee (MRCC), Ref: NIMR/HQ/R.8c/Nol. I/1185. Meetings were held with community leaders of each village, where the purpose and procedures of the study were explained, and permission was sought from the communities to inspect the mosquito larval habitats and sample larvae in their respective villages.

\section{Consent for publication}

This manuscript has been approved for publication by the National Institute of Medical Research, Tanzania (NIMR/HQ/P.12 VOL XXX/15).

\section{Competing interests}

The authors declared that they have no competing interests.

\section{Author details}

${ }^{1}$ Environmental Health and Ecological Sciences Department, Ifakara Health Institute, P.O. Box 53, Ifakara, Tanzania. ${ }^{2}$ School of Public Health, Faculty of Health Sciences, University of the Witwatersrand, Park Town, Republic of South Africa. ${ }^{3}$ Institute of Biodiversity, Animal Health and Comparative Medicine, University of Glasgow, Glasgow, UK. ${ }^{4}$ School of Life Science and Bioengineering, Nelson Mandela African Institution of Science \& Technology, Arusha, Tanzania. ${ }^{5}$ Centre for Applied Entomology and Parasitology, School of Life Sciences, Keele University, Newcastle-under-Lyme, UK. ${ }^{6}$ Center for Biotechnology Research and Development, Kenya Medical Research Institute, Nairobi, Kenya.

Received: 31 March 2020 Accepted: 17 June 2020

Published online: 23 June 2020

\section{References}

1. Coetzee M, Koekemoer LL. Molecular systematics and insecticide resistance in the major African malaria vector Anopheles funestus. Annu Rev Entomol. 2013;58:393-412.

2. Mccann RS, Ochomo E, Bayoh MN, Vulule JM, Hamel MJ, Gimnig JE, et al. Reemergence of Anopheles funestus as a vector of Plasmodium falciparum in western Kenya after long-term implementation of insecticide-treated bed nets. Am J Trop Med Hyg. 2014;90:597-604.

3. Coetzee M, Fontenille D. Advances in the study of Anopheles funestus, a major vector of malaria in Africa. Insect Biochem Mol Biol. 2004;34:599-605.

4. Kaindoa EW, Matowo NS, Ngowo HS, Mkandawile G, Mmbando A, Finda $M$, et al. Interventions that effectively target Anopheles funestus mosquitoes could significantly improve control of persistent malaria transmission in south-eastern Tanzania. PLoS ONE. 2017;12:e177807.

5. Finda MF, Limwagu AJ, Ngowo HS, Matowo NS, Swai JK, Kaindoa E, et al. Dramatic decreases of malaria transmission intensities in Ifakara, southeastern Tanzania since the early 2000s. Malar J. 2018;17:362.

6. Swai JK, Mmbando AS, Ngowo HS, Odufuwa OG, Finda MF, Mponzi $W$, et al. Protecting migratory farmers in rural Tanzania using eave ribbons treated with the spatial mosquito repellent, transfluthrin. Malar J. 2019;18:414

7. Limwagu AJ, Kaindoa EW, Ngowo HS, Hape E, Finda M, Mkandawile G, et al. Using a miniaturized double-net trap (DN-Mini) to assess relationships between indoor-outdoor biting preferences and physiological ages of two malaria vectors, Anopheles arabiensis and Anopheles funestus. Malar J. 2019;18:282.

8. Muturi EJ, Kamau L, Jacob BG, Muriu S, Mbogo CM, Shililu J, et al. Spatial distribution, blood feeding pattern, and role of Anopheles funestus complex in malaria transmission in central Kenya. Parasitol Res. 2009;105:1041-6.

9. Gillies M, DeMeillon B. The Anophelinae of Africa South of the Sahara (Ethiopian zoogeographical region). Johannesburg: South African Institute for Medical Research; 1968. 
10. Djouaka R, Riveron JM, Yessoufou A, Tchigossou G, Akoton R, Irving H, et al. Multiple insecticide resistance in an infected population of the malaria vector Anopheles funestus in Benin. Parasit Vectors. 2016;9:453.

11. Riveron JM, Osae M, Egyir-yawson A, Irving H, Ibrahim SS, Wondji CS. Multiple insecticide resistance in the major malaria vector Anopheles funestus in southern Ghana: implications for malaria control. Parasit Vectors. 2016;9:504.

12. Menze BD, Riveron JM, Ibrahim SS, Irving H, Antonio-nkondjio C, Awonoambene $\mathrm{PH}$, et al. Multiple insecticide resistance in the malaria vector Anopheles funestus from northern Cameroon is mediated by metabolic resistance alongside potential target site insensitivity mutations. PLoS ONE. 2016;11:e0163261.

13. Morgan JC, Irving H, Okedi LM, Steven A, Wondji CS. Pyrethroid resistance in an Anopheles funestus population from Uganda. PLOS ONE. 2010;5:e11872.

14. Cuamba N, Morgan JC, Irving H, Steven A, Wondji CS. High level of pyrethroid resistance in an Anopheles funestus population of the Chokwe district in Mozambique. PLoS ONE. 2010;5:e11010.

15. Lwetoijera DW, Harris C, Kiware SS, Dongus S, Devine GJ, Mccall PJ, et al. Increasing role of Anopheles funestus and Anopheles arabiensis in malaria transmission in the Kilombero valley, Tanzania. Malar J. 2014;13:331.

16. WHO. Test procedures for insecticide resistance monitoring in malaria vector mosquitoes Global Malaria Programme. Geneva: World Health Organization; 2018.

17. Killeen GF. Following in Soper's footsteps: northeast Brazil 63 years after eradication of Anopheles gambiae. Lancet Infect Dis. 2003;3:663-6.

18. Geissbühler Y, Kannady K, Chaki PP, Emidi B, Govella NJ, Mayagaya V, et al. Microbial larvicide application by a large-scale, community-based program reduces malaria infection prevalence in urban Dar Es Salaam, Tanzania. PLoS ONE. 2009;4:e5107.

19. Fillinger U, Lindsay SW. Suppression of exposure to malaria vectors by an order of magnitude using microbial larvicides in rural Kenya. Trop Med Int Health. 2006;11:1629-42.

20. Gimnig JE, Ombok M, Kamau L, Hawley WA. Characteristics of larval anopheline (Diptera: Culicidae) habitats in western Kenya. J Med Entomol. 2001;38:282-8.

21. Mwangangi JM, Mbogo CM, Muturi EJ, Nzovu JG, Githure JI, Yan G, et al. Spatial distribution and habitat characterisation of Anopheles larvae along the Kenyan coast. J Vector Borne Dis. 2007:44:44.

22. Antonio-nkondjio C, Ndo C, Costantini C, Awono-ambene P, Fontenille D, Simard F. Distribution and larval habitat characterization of Anopheles moucheti, Anopheles nili and other malaria vectors in river networks of southern Cameroon. Acta Trop. 2009;112:270-6.

23. Ayala D, Costantini C, Ose K, Kamdem GC, Antonio-nkondjio C, Agbor J, et al. Habitat suitability and ecological niche profile of major malaria vectors in Cameroon. Malar J. 2009;8:307.

24. Coetzee M. Key to the females of Afrotropical Anopheles mosquitoes (Diptera: Culicidae). Malar J. 2020;19:70.

25. Koekemoer LL, Kamau L, Hunt RH, Coetzee M. A cocktail polymerase chain reaction assay to identify members of the Anopheles funestus (Diptera: Culicidae) group. Am J Trop Med Hyg. 2002;66:804-11.

26. R Development Core Team. A language and environment for statistical computing. Vienna: R Foundation for Statistical Computing; 2016.

27. Ferguson HM, Dornhaus A, Beeche A, Borgemeister C, Gottlieb M, Mulla MS, et al. Ecology: a prerequisite for malaria elimination and eradication. PLoS Med. 2010;7:e1000303.

28. Kaindoa EW, Ngowo HS, Limwagu A, Mkandawile G, Kihonda J, Masalu JP, et al. New evidence of mating swarms of the malaria vector, Anopheles arabiensis in Tanzania. Wellcome Open Res. 2017;2:88.

29. Kaindoa EW, Ngowo HS, Limwagu AJ, Tchouakui M, Hape E, Abbasi S, et al. Swarms of the malaria vector Anopheles funestus in Tanzania. Malar J. 2019;18:29.

30. Ngowo HS, Kaindoa EW, Matthiopoulos J, Ferguson HM, Okumu FO. Variations in household microclimate affect outdoor-biting behaviour of malaria vectors. Wellcome Open Res. 2017;2:102.
31. Minakawa N, Mutero CM, Githure JI, Beier JC, Yan G. Spatial distribution and habitat characterization of Anopheline mosquito larvae in western Kenya. Am J Trop Med Hyg. 1999;61:1010-6.

32. Freyvogel TA, Kihaule PM. Report on a limited anopheline survey at Ifakara, south-eastern Tanzania. Acta Trop. 1968;25:17-28.

33. Takken W, Verhulst NO. Host preferences of blood-feeding mosquitoes. Annu Rev Entomol. 2013;58:433-53.

34. Minakawa N, Seda P, Yan G. Influence of host and larval habitat distribution on the abundance of African malaria vectors in western Kenya. Am J Trop Med Hyg. 2002;67:32-8.

35. Mala AO, Irungu LW, Shililu JI, Muturi EJ, Mbogo CC, Njagi JK, et al. Dry season ecology of Anopheles gambiae complex mosquitoes at larval habitats in two traditionally semi-arid villages in Baringo, Kenya. Parasit Vectors. 2011:4:25.

36. Bond JG, Rojas JC, Arredondo-jime JI, Valle J, Williams T, Quiroz-martı H. Population control of the malaria vector Anopheles pseudopunctipennis by habitat manipulation. Proc Biol Sci. 2004;271:2161-9.

37. Dida GO, Anyona DN, Abuom PO, Akoko D, Adoka SO, Matano AS, et al. Spatial distribution and habitat characterization of mosquito species during the dry season along the Mara River and its tributaries, in Kenya and Tanzania. Infect Dis Poverty. 2018;7:2.

38. Matowo NS, Tanner M, Munhenga G, Mapua SA, Finda M, Utzinger J, et al. Patterns of pesticides usage in agriculture in rural Tanzania call for integrating agricultural and public health practices in managing insecticideresistance in malaria vectors. 2020. https://www.researchsquare.com/ article/rs-30046/v1. Accessed 1 June 2020.

39. Nkya TE, Akhouayri I, Kisinza W, David JP. Impact of environment on mosquito response to pyrethroid insecticides: facts, evidences and prospects. Insect Biochem Mol Biol. 2013;43:407-16.

40. Philbert A, Lyantagaye SL, Nkwengulila G. A review of agricultural pesticides use and the selection for resistance to insecticides in malaria vectors. Adv Entomol. 2014;2:120-8.

41. Msofe NK, Sheng L, Lyimo J. Land use change trends and their driving forces in the Kilombero valley floodplain, south-eastern Tanzania. Sustainability. 2019;11:505.

42. Alavaisha E, Lyon SW, Lindborg R. Assessment of water quality across irrigation schemes: a case study of wetland agriculture impacts in Kilombero valley, Tanzania. Water. 2019;11:671.

43. Pinda PG, Eichenberger C, Ngowo HS, Msaky DS, Abbasi S, Kihonda J, et al. The dominant malaria vector, Anopheles funestus from rural southeastern Tanzania, is more strongly resistant to insecticides than Anopheles arabiensis. 2020. https://www.researchsquare.com/article/rs-19762/v1. Accessed 1 June 2020.

44. Garba Y, Olayemi IK. Spartial variation in physicochemical characteristics of wetland rice fields mosquito larval habitats in Minna, north central Nigeria. In: International conference on agricultural, ecological and medical sciences. 2015. pp. 11-4

45. Mereta ST, Yewhalaw D, Boets P, Ahmed A, Duchateau L, Speybroeck N, et al. Physico-chemical and biological characterization of anopheline mosquito larval habitats (Diptera: Culicidae): implications for malaria control. Parasit Vectors. 2013;6:320.

46. Oyewole IO, Momoh OO, Anyasor GN, Ogunnowo AA, Ibidapo CA, Oduola OA, et al. Physico-chemical characteristics of Anopheles breeding sites: impact on fecundity and progeny development. Afr J Environ Sci Technol. 2009;3:447-52.

\section{Publisher's Note}

Springer Nature remains neutral with regard to jurisdictional claims in published maps and institutional affiliations. 